\title{
Limit growth of ice crystals under different temperature oscillations levels in nile Tilapia
}

\author{
Mirko Salomon Chávez GUTIÉRREZ ${ }^{1 *}$ Cintia Melgaço de OLIVEIRA ${ }^{1}$ Fernanda Ramos MELO, \\ Vivaldo SILVEIRA JÚNIOR ${ }^{1}$
}

\begin{abstract}
The degenerative effect of temperature fluctuations during storage time is a critical condition that needs to be quantitatively characterized in products where drip losses are appreciable. In this work, real storage conditions were reproduced using freezers modified to cause 3 levels of temperature fluctuation $( \pm 0, \pm 3, \pm 5 ; \pm 7$ ) during storage of Tilapia (Oreochromis sp), at temperature of $-18{ }^{\circ} \mathrm{C}$. The fast frozen tilapia muscle (freezing cabinet) was chosen to quantify the growth of ice crystals according to temperature fluctuations. The identification of crystals in the optical microscope as well as histological treatments and measurements using specific software has shown that the growth of ice crystals in the first days of storage follows an asymptote, whose final value is conditioned only by the level of temperature fluctuations regardless of initial diameter, which begins storage. It has also been found that the growth of crystals formed during rapid freezing rapidly develops according to temperature fluctuations to which the product has been subjected. This work also identified statistically significant differences in the equivalent diameter of crystals formed at the four proposed levels of temperature fluctuation with significance level of $\mathrm{p}<0.05$.
\end{abstract}

Keywords: freezing; recrystallization; cold chain; temperature oscillations.

Practical Application: The use of household appliances such as vertical freezers during controlled trials is an advantageous strategy because it represents problems that the food industry faces dealing with temperature fluctuations during the cold chain. In addition, a combination of scanning electron microscopy and optical microscopy techniques was efficiently used in this study to quantify the growth of ice crystals (equivalent diameter) during storage time. This combined methodology is a viable alternative to analyze numerous samples where the use of electron microscopy becomes costly.

\section{Introduction}

\subsection{Frozen fish consumption, global and national market and cold chain}

According to report of fishery and aquaculture activities of Food and Agriculture Organization of the United Nations (2012), these activities have provided the world about 148 million tons of fish in 2010 (with total value of US\$217.5 billion), of which about 128 million tons were used for direct consumption. Freezing technology is the major fish processing method for direct human consumption, representing $55.2 \%$ of total processed fish for direct human consumption. In Brazil, according to Instituto Brasileiro de Geográfia e Estatística (2014), nile tilapia was the most established species, with production of 198,490 tons, equivalent to $41.9 \%$ of the total fish produced. This species showed an increase of $17.3 \%$ in relation to the 2013 production. The freezing of products of animal origin such as fish muscle at temperatures between $0{ }^{\circ} \mathrm{C}$ and $-2{ }^{\circ} \mathrm{C}$ ensures inhibiting the growth of bacteria and enzymatic deterioration reactions without causing cell damage to the product. However, it is known that the use of this conservation method usually results in undesirable physical, chemical and structural changes that can cause losses in texture, taste and color (Kane et al., 1997). In practice, throughout the cold chain, frozen products are exposed to unintentional temperature fluctuations due to various factors such as temperature control limits of refrigeration systems, project deficiencies, door openings (cold environments), inadequate transport operations, extended permanence in warehouses with different temperatures, etc. With regard to frozen fish processing, muscle is submitted to loss of moisture during freezing, and there are also factors that influence exudation due to the location and size of ice crystals formed (Chevalier et al., 2000).

\subsection{Temperature fluctuations during storage}

Since temperature fluctuations are frequent during transport, storage and distribution of frozen foods, some authors have studied changes in the structure of frozen products during storage periods under controlled temperature. Kaale \& Eikevik (2013) histologically characterized the size of ice crystals in the red and white muscle of Atlantic salmon (Salmo salar) during the super-freezing process and subsequent storage. Using frozen samples and temperature data measured on the surface, middle and center of salmon fillets, the authors presented an ice crystal size profile, differentiating the morphology of crystals corresponding to red and white salmon muscle. Although in this

${ }^{1}$ Laboratório de Automação e Controle de Processos de Alimentos - LACPA, Departamento de Engenharia de Alimentos - DEA, Faculdade de Engenharia de Alimentos - FEA, Universidade Estadual de Campinas - UNICAMP, Campinas, SP, Brazil

*Corresponding author: mirkobras@gmail.com 
work the authors present the evolution of ice crystals during the storage time, they did not report the temperature changes that occurred during this period. Margeirsson et al. (2012) evaluated the relationship between quality deterioration of cold cod fillets packaged in three types of EPS boxes. A reduction in the shelf life of 1.5 and 3 days was observed in boxes stored under variable temperature compared to those stored at constant temperature. In all these works, temperature variations do not represent the real conditions that frozen products are submitted during transport and especially during storage. In products such as fish meat, where water losses are appreciable, it is necessary to quantify the negative impact that temperature changes cause in the food structure. Reproducing real storage conditions under controlled temperature fluctuations makes it possible to predict the recrystallization behavior in food during storage, in addition to technical information to assist in estimating the shelf life of stored products.

\section{Material and methods}

The experimental methodology used in this work is presented in Figure 1 below:

\subsection{Conditioning of Tilapia samples}

The raw material, object of this study, was Thailand Tilapia (Oreochromis SP). Samples were bought in a near fishing company located in Campinas-SP, Brazil. Eighteen tilapia fillets have been conditioned and transported in polystyrene boxes to the Laboratory of Automation and Food Process Control, Faculty of Food Engineering at UNICAMP. Samples were immediately transported to the laboratory in polyethylene boxes and placed in contact with ice scales in several layers to prevent the onset of deterioration reactions until the beginning of the rapid freezing.

\subsection{Freezing of samples and characterization of samples before storage}

Eighteen tilapia fillets weighting between 0.25 and $0.45 \mathrm{~kg}$ were frozen using a freezing cabinet (White Martins Praxair Inc., Nro. 12055), which received nitrogen vapor injection through a hose from a tank. According to tests with model solutions in this cabinet by Davila-Monzón \& Silveira (2014), this equipment develops an average freezing rate of $0.060^{\circ} \mathrm{C} / \mathrm{s}$, which according to the freezing rate classification proposed by Dinçer (2003), it is a rapid freezing process. After this step, frozen fish was submitted to scanning electron microscopy to examine and record the initial morphology of muscles before starting treatment (frozen storage). Samples were lyophilized and then cut into $10 \times 20 \mathrm{~mm}$ slices to achieve the cryogenic fracture. Subsequently, the total weight of fish samples was divided into 4 sub-samples of $1250 \mathrm{~g}$, which were taken to the 4 freezers conditioned to recreate the 3 levels of temperature oscillation and a freezer used as reference without any programmed temperature oscillation

\subsection{Adaptation of the test chamber}

To ensure that storage under temperature fluctuations develops in a continuous manner, without power disconnections and under controlled room temperature conditions, it was necessary to adjust the $16 \mathrm{~m}^{2}$ test chamber present at the Laboratory of Automation and Control and Food Processes (LACPA) DEA / FEA / UNICAMP. This chamber was thermally insulated and had a temperature compensation system. In this physical space, freezers used in the storage of frozen sample have been allocated. The temperature inside the chamber was kept at $25^{\circ} \mathrm{C}$ during the entire storage time, so that oscillations of freezers have constant periods, alternating the use of an electric resistance and a $7500 \mathrm{BTU}$ air conditioner module for heating and cooling respectively; both devices are controlled by an electronic temperature controller NOVUS ${ }^{\circledR}$ model N323.

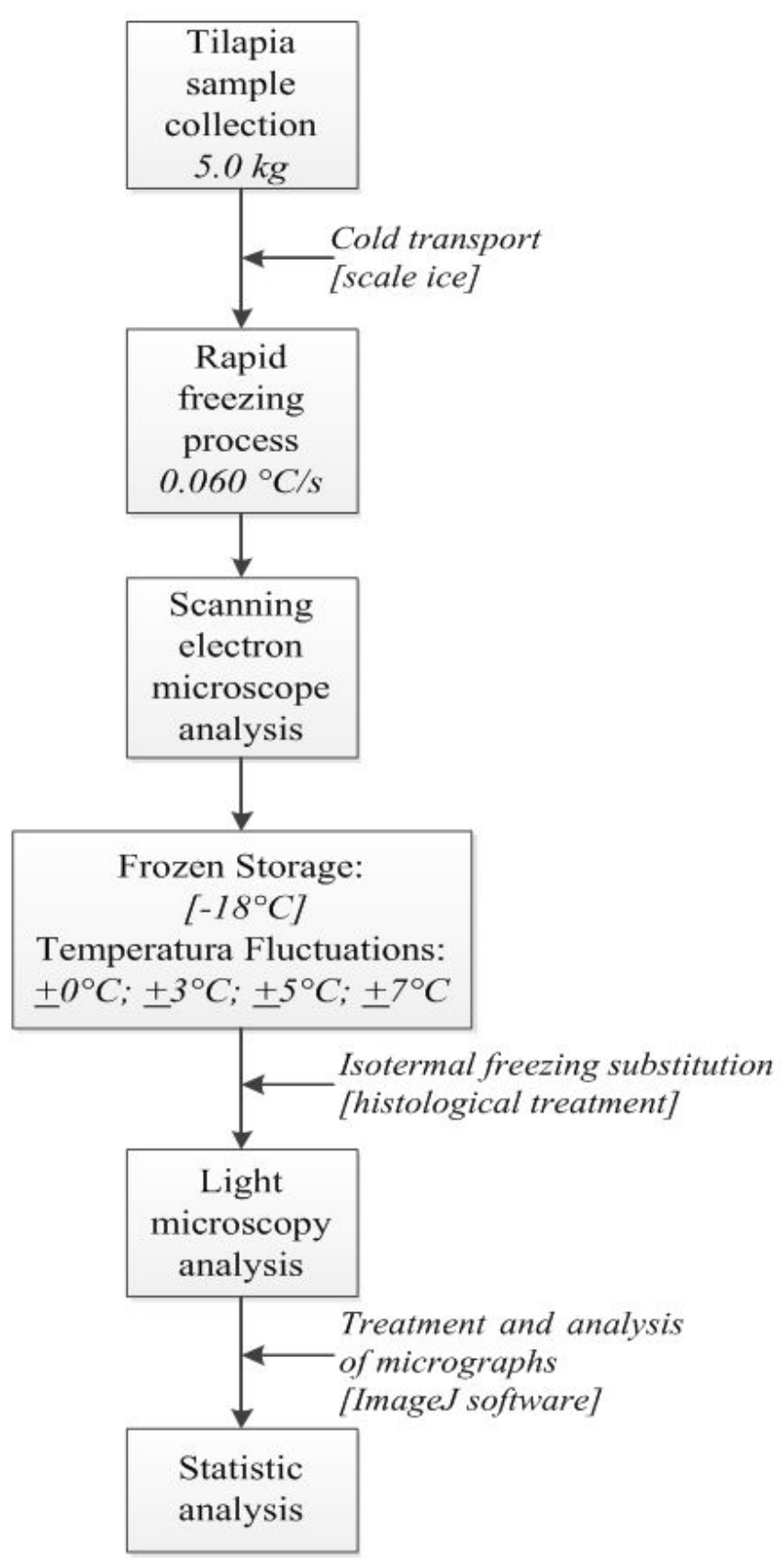

Figure 1. Experimental methodology for analysis of ice crystals in fast frozen tilapia muscle submitted to various levels of temperature oscillation. 


\subsection{Frozen storage under temperature fluctuations and temperature monitoring}

Cooling systems used for the storage of samples were four freezers model BVR28GB-BRASTEMP ${ }^{\circledR}$. These freezers have capacity of 228 liters and allow storage up to temperature of $-26^{\circ} \mathrm{C}$. Door seal and closing have been reinforced to prevent moisture and environment heat Infiltration. Temperature was controlled by an on-off digital controller NOVUS ${ }^{\circledR} \mathrm{N} 323$. Once controllers were installed in each freezer, the operating temperature was set at $-18^{\circ} \mathrm{C}$. The internal temperature fluctuations in freezers were caused by programming controllers in the control differential value (hysteresis) in three levels $( \pm 3.0 ; \pm 5.0$ and \pm 7.0 ), being also necessary to adjust the set point, upper and lower set point limit and control delay time parameters. One of the freezers has been programmed to operate with hysteresis level zero, that is, without any oscillation; the freezer was used as a reference and compared to the three temperature oscillation levels proposed during the 90 days of frozen storage. The temperature in each of the four freezers was monitored at frequency of 10 minutes using a set of 3 PT-100 temperature sensors located at the top, middle and bottom of the freezer. For samples, a three-wire PT100 temperature sensor class B DIN IEC 751 with ceramic insulation was used. This sensor was located and fixed at the center of each sample. All temperature sensors are connected in the FIELDLOGGER NOVUS ${ }^{\mathrm{m}} \mathrm{virtual}$ register. With temperature data recorded in the recorder's internal memory in the format of data sheets, it was possible to build time-temperature graphs for each of the systems during the storage time.

The thermal behavior of a household refrigerator when submitted to door opening and closing can be approached in different ways, moreover, to standardize the conditions to which freezers were submitted, the temperature in the test chamber was maintained at $25^{\circ} \mathrm{C}$ for all tests. Thus, the heat infiltration rate resulting from this temperature difference was uniform for all 4 freezers. The storage in each of the freezers started after reaching the steady temperature state at $-18^{\circ} \mathrm{C}$. The time required to reach this temperature and keep it has been experimentally determined for a test at room temperature (in the chamber) of $25^{\circ} \mathrm{C}$. In this assay, it was observed that the time necessary for the 4 freezers to reach the temperature of $-18^{\circ} \mathrm{C}$ was approximately 152 minutes. This preliminary test was also used to evaluate the ability to maintain the chamber temperature close to the set value, regardless of changes in outside temperature during a minimum period of 24 hours. With regard to the operation of freezers, this test also identified that the 4 freezers were programmed to work at the same set point temperature (SP) and hysteresis value zero.

\subsection{Microscopy analysis}

This work followed methodology proposed by Melorose et al. (2015), for preparing samples for observation on an optical microscope; thus, from each fish sample stored in the freezer, a fragment of approximately $5 \mathrm{~cm}$ was collected using a scalpel. The cut was made transversely to the muscle fiber. This procedure was performed inside the freezer in an attempt to minimize changes in storage temperature. Then, an indirect fixation method called substitution by isothermal freezing proposed in literature (Kaale \& Eikevik, 2013; Alizadeh et al., 2007; Zaritzky \& Martino,
1988) was used to observe the gaps left by ice crystals in the fish tissue. After staining, samples were placed and sealed on $26 \times 76 \mathrm{~mm}$ microscope slides. Slides with prepared samples were observed in Carl Zeiss -Jenaval ${ }^{\circledR}$ optical microscope, which allows magnification of 500 times at high resolution. This microscope has a Hitachi digital camera for image analysis. Images were recorded and processed using open source JAVA ${ }^{\circledR}$ software for analysis of IMAGEJ ${ }^{\circledR}$ images. Pore diameter, initially measured in pixels was converted into microns using the same software. The spatial measurements of analyzed objects originally expressed as number of pixels, were calibrated using micrometric rule for standard microscope. The parameters considered to study the growth of ice crystals were equivalent diameter and cross-sectional area. The cross-sectional area refers to the surface area of the cross section of an object (crystals or muscle fiber). Equivalent diameter is defined as the diameter of a circle that is represented by the same area of the object (crystal) being studied. During the stage of image processing and to be able to select only ice crystals using differentiation tool called "tresholding", "Plugin" called "Cell Magic Wand" was used. This allows interactive segmentation of cells selected in a region of interest. Next, the software evaluated area and the shape parameters of crystals. For each oscillation level, 80 micrographs were taken. Samples from each of the 4 freezers were collected at intervals of 3 days due to the time required to dehydrate samples in the substitution step by isothermal freezing.

\subsection{Statistical analysis}

To determine whether there were differences among oscillation levels, one-way analysis of variance (ANOVA) was applied and then the Tukey test was used to identify which treatments are different from each other at statistical significance level of $\mathrm{p}<0.05$.

\section{Results and discussion}

\subsection{Controlled temperature oscillations}

The ability of freezers to maintain the set temperature is different. This behavior can be explained by limitations of $\mathrm{ON} / \mathrm{OFF}$ type control used in household refrigeration systems and by defects on the project itself. Once in later trials, three ascending oscillation levels according to the inherent oscillation level of equipment determined in the preliminary test will be evaluated; the freezers were organized as follows (Table 1):

Once freezers were organized according to their ability to maintain the SETPOINT, the next step was to be able to keep the storage temperature of $-18{ }^{\circ} \mathrm{C}$, oscillating within programmed limits of $\pm 3.0 ; \pm 5.0 ; \pm 7.0$ and $\pm 0.0^{\circ} \mathrm{C}$. To cause

Table 1. Classification and distribution of freezers proposed for tests with controlled temperature fluctuations.

\begin{tabular}{ccc}
\hline $\begin{array}{c}\text { Treatment } \\
\text { Codification }\end{array}$ & Oscillation level $\left({ }^{\circ} \mathrm{C}\right)$ & Equipment used \\
\hline $\mathrm{N}_{0}$ & \pm 0.0 & Freezer 4 \\
$\mathrm{~N}_{3}$ & \pm 3.0 & Freezer 3 \\
$\mathrm{N}_{5}$ & \pm 5.0 & Freezer 1 \\
$\mathrm{N}_{7}$ & \pm 7.0 & Freezer 2 \\
\hline
\end{tabular}


these oscillations, the following parameters were adjusted: set point, set point low, set point high and hysteresis in the electronic controller configuration. Since NBR12863 standard warns that temperature monitoring tests should not be developed in time periods shorter than 20 hours, the system monitoring was performed for 40 hours. The monitoring result can be seen in Figure 2, below:

Figure 2 shows that the temperature inside the 4 freezers oscillated very closely to the programmed level $\left(-18^{\circ} \mathrm{C}\right)$. Although oscillation values were not exactly achieved, it was observed that in all freezers, upper temperature threshold (positive variation) was reached or exceeded by approximately $1.5^{\circ} \mathrm{C}$. Thus, the hypothesis of potential damage with increased temperature in the food matrix could be evaluated during storage.

\subsection{Results of scanning electron microscopy analyses}

Typical fish muscle fiber can be seen surrounded by the sarcolemma and endomysial connective tissue, which is mainly composed of collagen (Melorose et al., 2015). The separation that can be seen among muscle cells is generally attributable to the effect produced by chemical fixation and dehydration during preparation for SEM. Thus, the sarcolemma integrity and the surface structure are characteristics that may show changes during the freezing process. The longitudinal views of

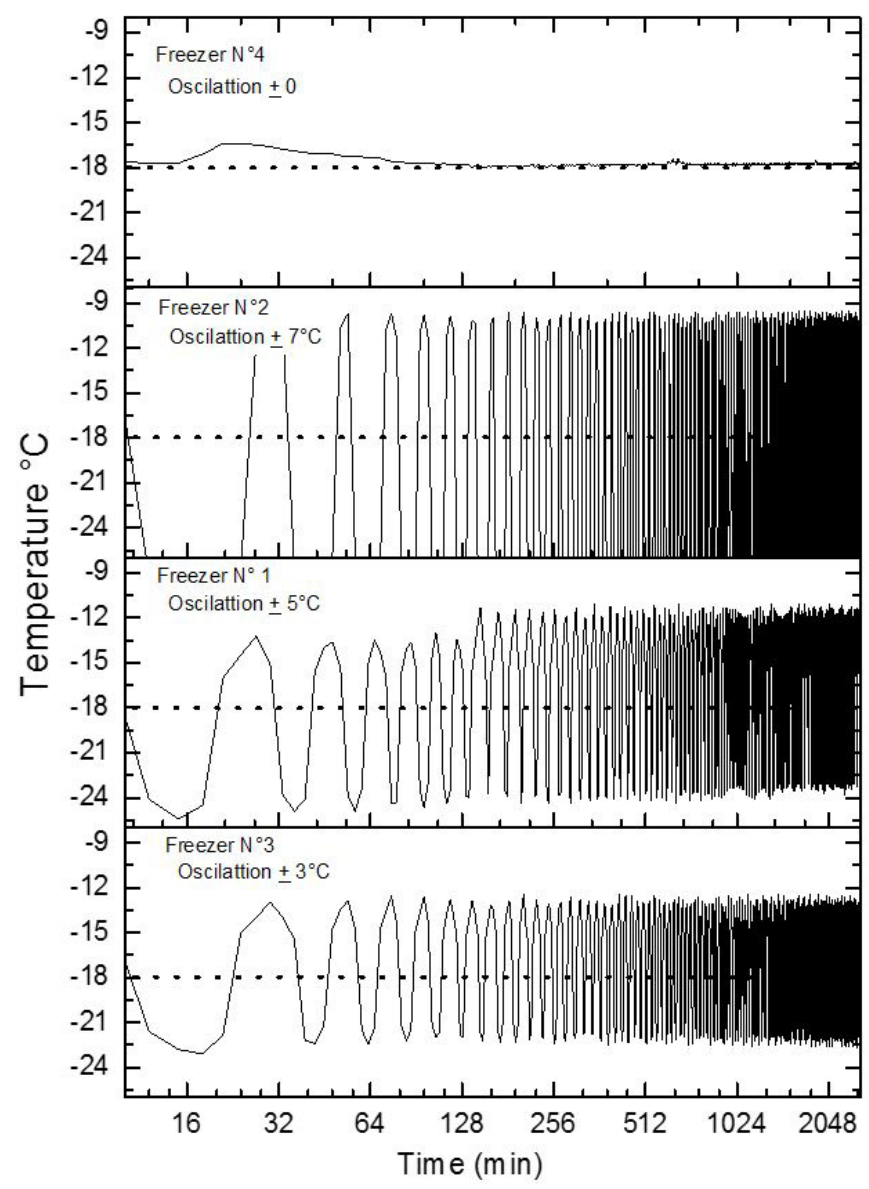

Figure 2. Temperature oscillations programmed in freezers used during frozen storage. frozen samples indicate the occurrence of muscle fiber packets distorted during freezing. In Figure 3, this distortion is evident from the nature of the interstitial fish muscle cluster.

This micrograph also shows small interstitial spaces among muscle fiber bundles $\left(\mathrm{N}^{\circ} 4\right)$, and these areas would presumably be places of deposition or formation of ice crystals $\left(\mathrm{N}^{\circ} 1, \mathrm{~N}^{\circ} 2\right.$ and $\left.\mathrm{N}^{\circ} 3\right)$. Figure 3 shows small intracellular holes that were presumably formed during the rapid freezing process $\left(\mathrm{N}^{\circ} 5, \mathrm{~N}^{\circ} 6\right.$ and $\left.\mathrm{N}^{\circ} 7\right)$. Furthermore, some extracellular spaces resulting from the possible shrinkage of muscle fibers during the beginning of rigor mortis can also be observed (Payne et al., 1994). It is noteworthy that in all micrographs analyzed, it was possible to observe small holes along the fish muscle, which evidenced the formation of smaller-size ice crystals. This muscle profile after freezing was shown by (Mohr \& Reid, 1985) for bovine meat samples and also by (Payne et al., 1994), who used liquid nitrogen to achieve faster cooling rates and prevent the formation of large intracellular ice crystals.

\subsection{Evolution of ice crystals during frozen storage at different temperature oscillation levels}

The analysis of micrographs obtained from the optical microscope showed the growth behavior of the diameters of ice crystals in samples during the 30 days of storage. With the average values of the equivalent diameter $\left(\mathrm{D}_{\mathrm{eq}}\right)$ measured at each sampling day, it was possible to study the evolution of the size of ice crystals as a function of temperature oscillation levels. Thus, after the first 24 hours of storage, samples showed approximately the same equivalent diameter. For comparison purposes, values of $14.03 \mu \mathrm{m}$ and $18.08 \mu \mathrm{m}$ obtained for treatments $\mathrm{N}_{0}$ and $\mathrm{N}_{7}$ were observed, respectively. Although these values are numerically different, statistical analysis showed that there was no statistically significant difference among the four treatments in the first day of storage. From the third day of storage on, greater difference among samples was found, especially in samples

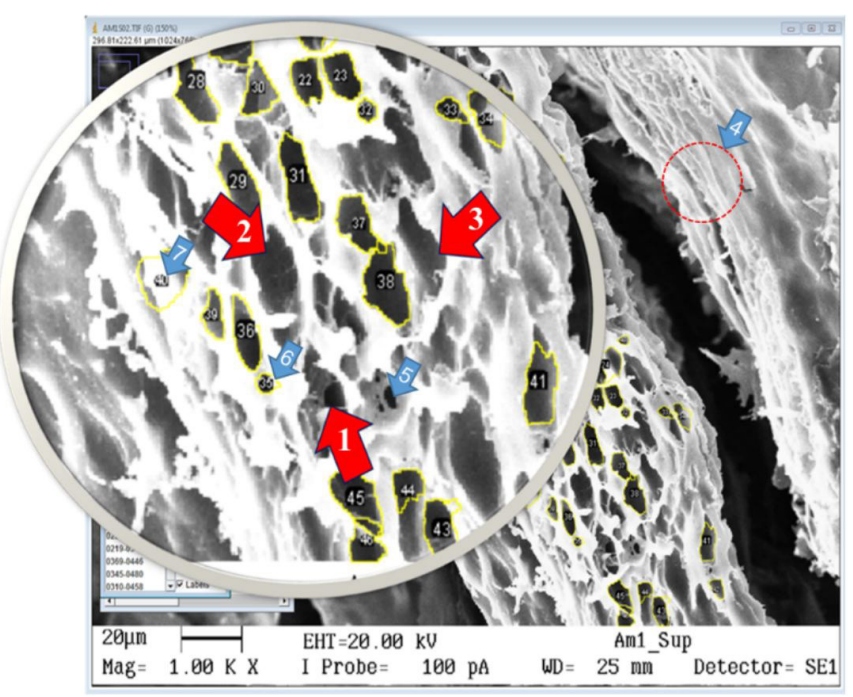

Figure 3. Micrographs of a longitudinal section of Tilapia muscle frozen at $-40{ }^{\circ} \mathrm{C}$. Cell membranes have been damaged by the penetration of ice crystals during their growth on the surface. 
from treatment $\mathrm{N}_{7}$, where an increase of approximately $140 \mu \mathrm{m}$ up to the sixth day of sampling was observed, a behavior also reported by Kaale \& Eikevik (2013) in white salmon muscle samples frozen at $-30{ }^{\circ} \mathrm{C}$ subsequently stored at $-1.7 \pm 0.3{ }^{\circ} \mathrm{C}$. According to these authors, this significant increase is due to two factors: firstly, the great difference between freezing temperature and storage temperature, which in our study were $-40^{\circ} \mathrm{C}$ and $-18.0+7^{\circ} \mathrm{C}$, respectively. This temperature gradient causes the growth of ice crystals, particularly small ones that were formed on the sample surface; secondly, the effect of temperature fluctuations that were produced during the freezing process. It is important to mention that although Kaale et al. (2011) stated that temperature fluctuations result in recrystallization
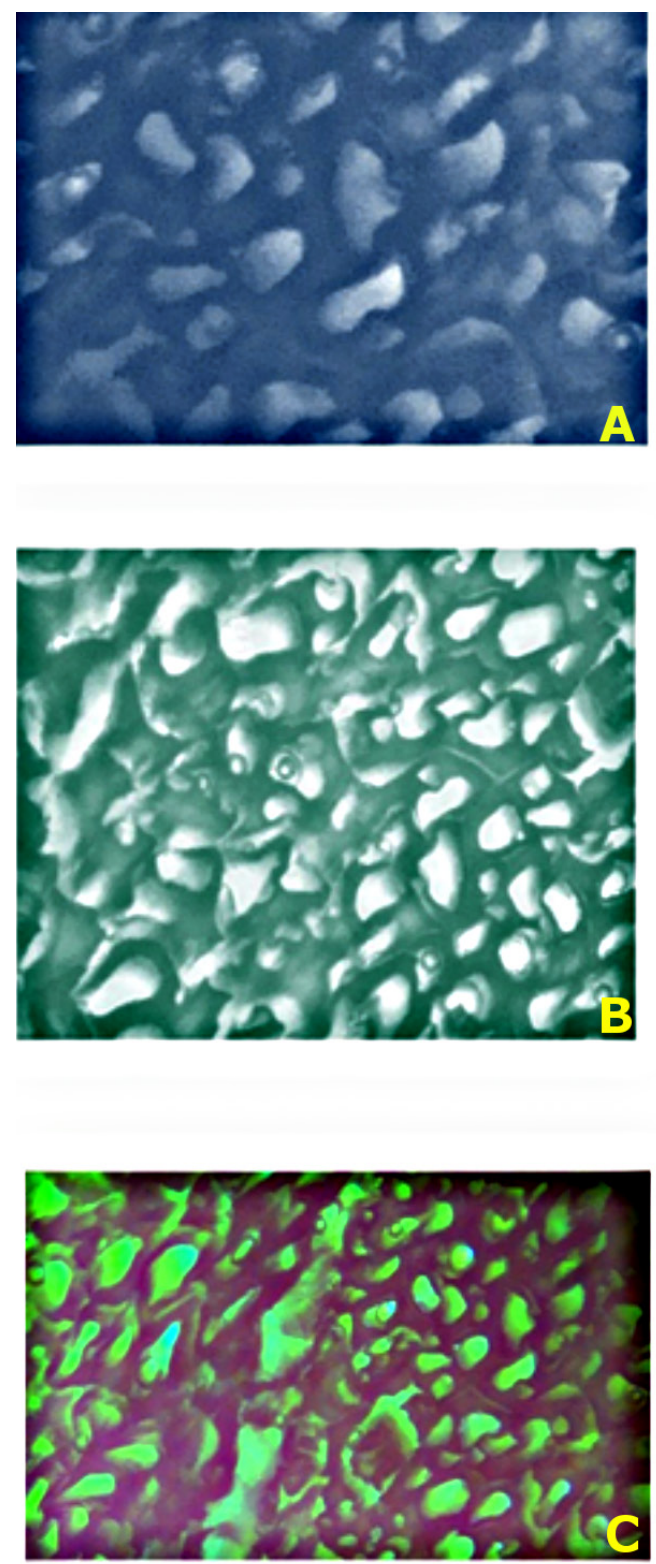

processes, the storage temperature was considered stable at $1.7 \pm 0.3{ }^{\circ} \mathrm{C}$ by these authors. In other words, temperature oscillations were disregarded, since how this temperature was monitored, or how this temperature condition was achieved throughout the tests were factors that have not been reported. A characteristic of samples in the first days of storage was the presence of crystals with more uniform and rounded shape, in all oscillation levels (Figure 4). It was also observed that the crystals are more numerous in the tissue structure. This feature contrasts with micrographs obtained on the last day of storage, where numerous cracks inside the fibers and deterioration of the peri-cellular connective tissue were observed. This effect was also reported by Bahuaud et al. (2008) in Salmon samples
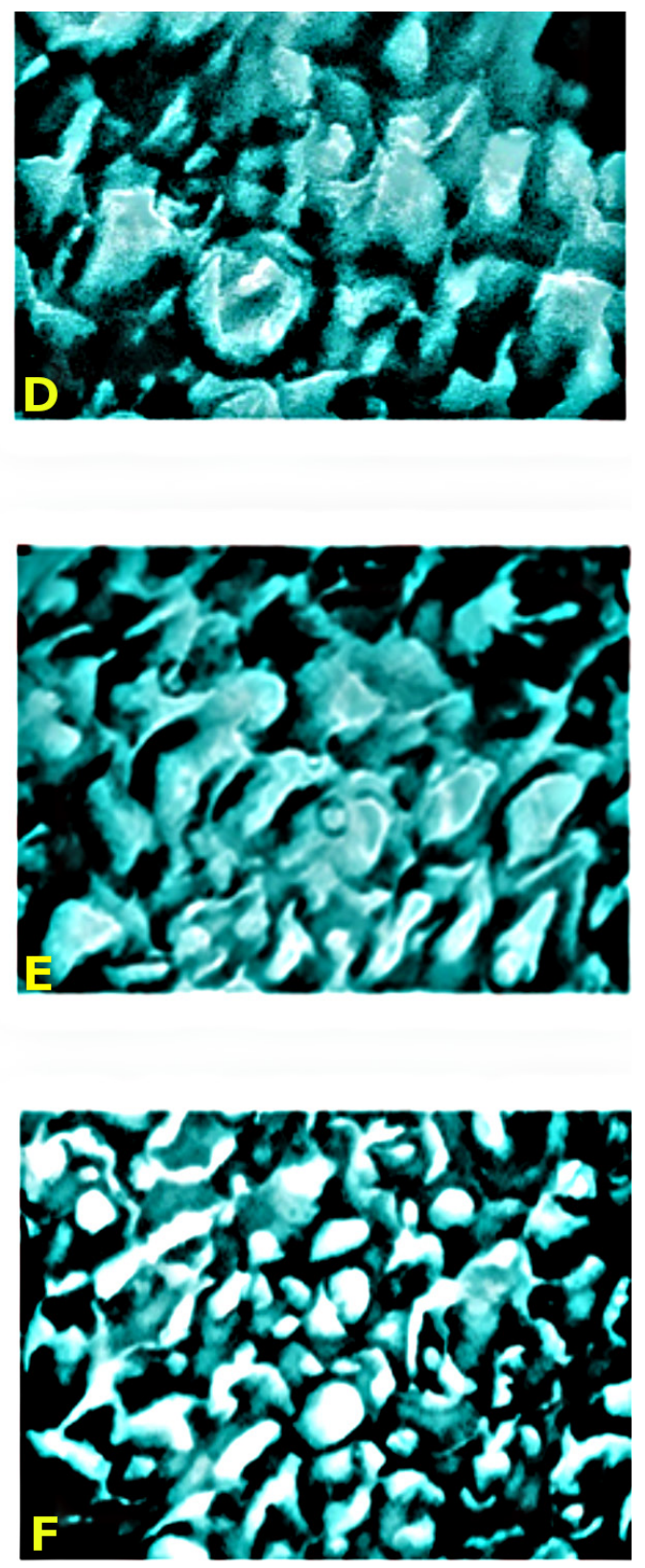

Figure 4. Micrographs obtained in the cross-section optical microscope of histologically treated tilapia muscle, submitted to different temperature oscillation levels during the first 30 days of frozen storage: (A) 3 days, $-18 \pm 7^{\circ} \mathrm{C}$; (B) 3 days, $-18 \pm 5^{\circ} \mathrm{C}$; (C) 3 days, $-18 \pm 0{ }^{\circ} \mathrm{C}$; (D) 30 days, $-18 \pm 7^{\circ} \mathrm{C}$; (E) 30 days, $-18 \pm 5^{\circ} \mathrm{C}$ and (F) 30 days, $-18 \pm 0{ }^{\circ} \mathrm{C}$. 
(Salmo salara) after 4 weeks of storage. Moreover, it could be inferred that in this study, in addition to the storage time, the effect of 4 oscillation levels were considered. The analysis of micrographs also shows that the development of ice crystals in samples follows an asymptotic behavior at all temperature oscillation levels. In addition, it was observed that from the $15^{\text {th }}$ day of storage, the growth of ice crystal stops, and the equivalent diameter in the subsequent days reaches almost constant values. This behavior was also reported by Martino \& Zaritzky (1989) in frozen bovine meat samples stored at $-5,-10,-15$ and $-20^{\circ} \mathrm{C}$.

However, the authors used a kinetic model generated from the equivalent diameters experimentally obtained to determine that throughout storage, the average equivalent diameters reached a value called "Limit diameter". This limit value is reached after a characteristic period of time, called "Limit time", which represents the time in which equivalent diameter values do not differ from each other in at most $3 \%$. With these results, the author states that the limit diameter is reached regardless of storage temperature and initial equivalent diameter. Unlike the results obtained by Zaritzky \& Martino (1988), this work found that the size of ice crystals increases according to oscillation levels that samples are submitted to. Thus, Table 2 shows that although samples initially had almost the same equivalent diameter value, the growth of crystals resulted in very different values, and comparatively, in the case of samples submitted to the highest oscillation level $\left(7^{\circ} \mathrm{C}\right)$, the average equivalent diameter estimated on the $30^{\text {th }}$ day of storage was almost three times the equivalent diameter value of samples with the lowest oscillation level estimated on that day. It could be inferred that there is a limit diameter for each temperature fluctuation level for a given storage condition, starting from the same freezing process. The crystal growth results shown in Table 2, confirm the hypothesis that temperature variation during frozen storage promotes the growth of crystals originated from the fusion of small crystals formed during rapid freezing. Additionally, Table 2 shows that the size of crystals measured during 30 days of storage had high growth when compared with results of Kaale \& Eikevik (2013), where, on the $28^{\text {th }}$ day of storage, the authors reported equivalent diameters of crystals on the surface of white salmon muscle of $134 \mu \mathrm{m}$, and for red salmon muscle, the authors reported equivalent diameter of $63 \mu \mathrm{m}$, with standard deviations of \pm 4 and $\pm 2 \mu \mathrm{m}$, respectively. This difference can be explained by the storage temperature of $-1.7 \pm 3{ }^{\circ} \mathrm{C}$. The temperature oscillation value is much lower than oscillation values proposed in this work; however, compared with the oscillation level in control $\mathrm{N}_{0}$, values were closer. A characteristic of samples in the early days of storage was the presence of crystals with more uniform and round shape in temperature oscillation levels. It was also observed that the crystals are more numerous in the tissue structure. This feature contrasts with micrographs obtained on the last day of storage, where numerous cracks inside the fibers and deterioration in the peri-cellular tissue were observed (Figure 4). This effect was also reported by Bahuaud et al. (2008) in salmon samples (Salmo salara) after 4 weeks of storage.

\subsection{Results of statistical analysis}

The equivalent diameter values of ice crystals measured in samples with 4 temperature oscillation levels were statistically analyzed using the average value calculated for each sampling day. Then, average values were submitted to analysis of variance (ANOVA), which found that there is a statistically significant difference among averages calculated with 5\% significance level. Since there are differences among averages, the Tukey's test was applied to determine the difference in equivalent diameter results obtained from each oscillation level. The results are shown in Table 2. From values shown in Figure 3, it was quantitatively evaluated that as the temperature oscillation levels increase, the equivalent diameter of ice crystals formed in the tissue structure also increases, as well as the limit diameter. Over the 30 days of storage, the equivalent diameter values obtained are statistically different, except for the first day of storage, where statistically similar results for treatments $\mathrm{N}_{3}$ and $\mathrm{N}_{5}$ can be verified. After the third day of storage, the difference between the size of crystals obtained in all oscillation levels is quite evident. However, to confirm the reliability of results, confidence intervals corresponding to the average values of each oscillation level were calculated for the first 30 days of storage (Figure 5).

Table 2. Equivalent diameter values of ice crystals (average + standard deviation) $[\mu \mathrm{m}]$, measured in each sampling day, according to the programmed temperature oscillation level.

\begin{tabular}{|c|c|c|c|c|}
\hline \multirow{2}{*}{ Day } & \multicolumn{4}{|c|}{ Oscillation level $\left[{ }^{\circ} \mathrm{C}\right]$} \\
\hline & \pm 0.0 & \pm 3.0 & \pm 5.0 & \pm 7.0 \\
\hline 0 & $14.063^{\mathrm{D}} \pm 1.871$ & $15.338^{\mathrm{B}} \pm 2.703$ & $15.463^{\mathrm{B}} \pm 2.687$ & $18.803^{\mathrm{A}} \pm 2.137$ \\
\hline 3 & $44.355^{\mathrm{D}} \pm 2.301$ & $80.100^{C} \pm 2.589$ & $103.016^{\mathrm{B}} \pm 3.001$ & $124.332^{\mathrm{A}} \pm 2.471$ \\
\hline 6 & $72.518^{\mathrm{D}} \pm 3.202$ & $130.684^{\mathrm{C}} \pm 5.942$ & $159.065^{\mathrm{B}} \pm 3.230$ & $260.710^{\mathrm{A}} \pm 2.256$ \\
\hline 9 & $80.675^{\mathrm{D}} \pm 1.047$ & $157.012^{\mathrm{C}} \pm 3.270$ & $163.018^{\mathrm{B}} \pm 3.172$ & $269.989^{\mathrm{A}} \pm 2.011$ \\
\hline 12 & $84.110^{\mathrm{D}} \pm 2.114$ & $180.848^{\mathrm{B}} \pm 2.892$ & $169.266^{C} \pm 3.035$ & $277.780^{\mathrm{A}} \pm 2.132$ \\
\hline 15 & $111.639^{\mathrm{D}} \pm 3.009$ & $181.082^{\mathrm{C}} \pm 3.795$ & $200.803^{\mathrm{B}} \pm 5.502$ & $300.975^{\mathrm{A}} \pm 2.243$ \\
\hline 18 & $102.701^{\mathrm{D}} \pm 5.332$ & $179.549^{\mathrm{C}} \pm 2.817$ & $205.330^{\mathrm{B}} \pm 2.504$ & $311.782^{\mathrm{A}} \pm 1.605$ \\
\hline 21 & $100.995^{\mathrm{D}} \pm 5.449$ & $182.088^{\mathrm{C}} \pm 2.776$ & $243.667^{\mathrm{B}} \pm 2.047$ & $320.810^{\mathrm{A}} \pm 1.544$ \\
\hline 24 & $184.295^{\mathrm{C}} \pm 2.740$ & $184.295^{\mathrm{C}} \pm 2.740$ & $245.225^{\mathrm{B}} \pm 2.034$ & $316.418^{\mathrm{A}} \pm 1.566$ \\
\hline 27 & $106.283^{\mathrm{D}} \pm 5.104$ & $188.252^{\mathrm{C}} \pm 2.679$ & $251.901^{\mathrm{B}} \pm 1.978$ & $314.813^{\mathrm{A}} \pm 1.574$ \\
\hline 30 & $109.134^{\mathrm{D}} \pm 4.938$ & $190.560^{\mathrm{C}} \pm 2.645$ & $248.559^{\mathrm{B}} \pm 2.006$ & $316.198^{\mathrm{A}} \pm 1.567$ \\
\hline
\end{tabular}

Values shown with the same letter on the same line are not significantly different $(\mathrm{p}<0.05)$ 


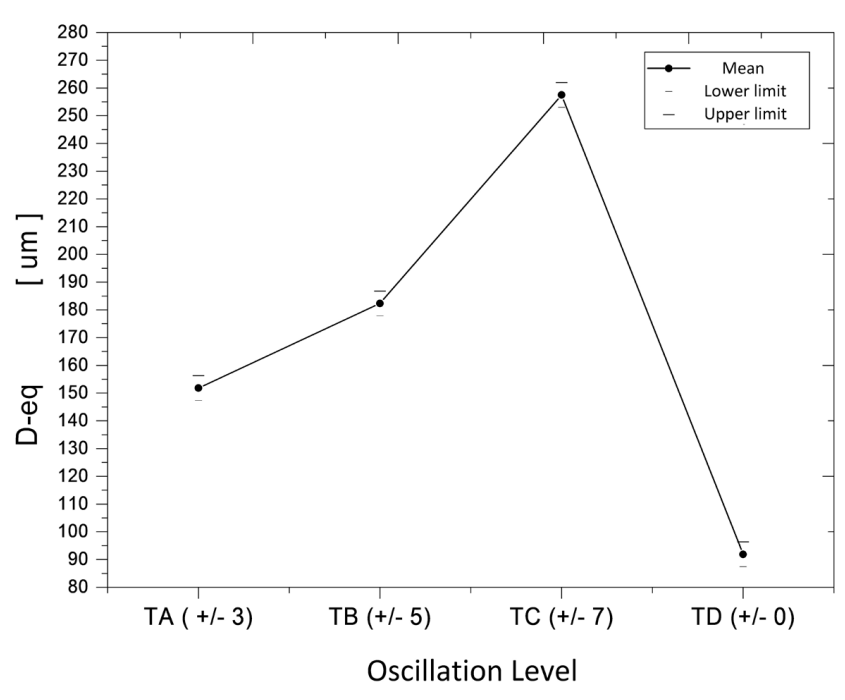

Figure 5. Mean equivalent diameter of ice crystals estimated at the 30 th day for each treatment with confidence intervals calculated at $95 \%$ confidence.

The estimated results indicate low values and quite distanced from confidence intervals, confirming the reliability of the diameter equivalent values measured during the tests, while pointing out a wide difference among results of treatments applied. Therefore, it could be said that the growth of crystals during storage is highly conditioned by temperature oscillation levels to which food is exposed during the storage time. Statistically, it was shown that distinct fluctuations produce crystals of different equivalent diameters, even at very close temperature gradients.

\section{Conclusions}

Household refrigeration devices such as freezers may be used for representing and studying changes and detrimental effects that occur during storage at controlled temperatures.

With SEM micrographs, it was possible to identify and characterize by comparison, the spaces corresponding to smaller-size ice crystals characteristic of rapid cooling rates and by means of observation in optical microscope, it was possible to measure and calculate the equivalent size and diameter of ice crystals formed during the storage time under controlled temperature oscillations. Thus, it could be concluded that the combination of scanning electron microscopy techniques (SEM) and optical microscopy proved to be appropriate to study the evolution of ice crystals after freezing process and subsequent storage. This combined approach may represent a viable alternative to analysis of numerous samples where the use of electron microscopy becomes costly. In addition, regarding the methodology used in this work, it is important to note that although the histology treatment used for fixing and replacing the sample observed in this work needed 3 days to complete the replacement of ice crystals, this method is as efficient as dehydration by lyophilization suggested by some authors.

Most of the growth (in all samples) was observed in the first 6 days of storage, subsequently, after day 12, it was observed in all treatments that the crystal growth has stabilized at nearly constant values, but statistically different. It could be concluded that the growth of ice crystals formed during the rapid freezing process will quickly develop, depending on temperature fluctuations to which samples are submitted. It should be mentioned that this behavior differs from some authors who have theorized about a final diameter limit. In this work, this was not identified, but it was found that the growth of crystals during storage reach different final limits, because it is closely linked to temperature fluctuation levels. Thus, statistically significant differences have been demonstrated among the four oscillation levels proposed in this work with significance level of $\mathrm{p}<0.05$.

Once the statistical analysis showed significant differences among crystal growth results according to temperature fluctuation levels chosen in this study, it could be conclude that there is a directly proportional relationship between temperature gradient and size of crystals formed, even at quite close temperature oscillation values. This result emphasizes the need to achieve storage temperatures increasingly stable, since even with fluctuations considered commercially acceptable such as $\pm 3^{\circ} \mathrm{C}$, it was verified that the ice crystals formed during rapid freezing process will increase their size by up to 10 times during the first 2 weeks of storage.

\section{References}

Alizadeh, E., Chapleau, N., Lamballerie, M., \& Le-Bail, A. (2007). Effect of different freezing processes on the microstructure of Atlantic salmon (Salmo salar) fillets. Innovative Food Science \& Emerging Technologies, 8(4), 493-499. http://dx.doi.org/10.1016/j. ifset.2006.12.003.

Bahuaud, D., Mørkøre, T., Langsrud, Ø., Sinnes, K., Veiseth, E., Ofstad, R., \& Thomassen, M. S. (2008). Effects of $-1.5^{\circ} \mathrm{C}$ Super-chilling on quality of Atlantic salmon (Salmo salar) pre-rigor Fillets: cathepsin activity, muscle histology, texture and liquid leakage. Food Chemistry, 111(2), 329-339. PMid:26047431. http://dx.doi.org/10.1016/j. foodchem.2008.03.075.

Chevalier, D., Sequeira-Munoz, A., Le Bail, A., Simpson, B. K., \& Ghoul, M. (2000). Effect of freezing conditions and storage on ice crystal and drip volume in turbot (Scophthalmus maximus). Innovative Food Science \& Emerging Technologies, 1(3), 193-201. http://dx.doi. org/10.1016/S1466-8564(00)00024-2.

Davila-Monzón, L., \& Silveira, V. Jr. (2014). Avaliação da cristalização do gelo em gelatina a diferentes velocidades de congelamento e recristalização em diferentes condições de estocagem. Campinas: Universidade Estadual de Campinas.

Dinçer, I. (2003). Food freezing: refrigeration systems and applications. Hoboken: John Wiley \& Sons.

Food and Agriculture Organization of the United Nations. (2012). The state of world fisheries and aquaculture (pp. 19-24). Rome: FAO.

Instituto Brasileiro de Geográfia e Estatística. (2014). Produção da Pecuária Municipal (pp. 25-27). Rio de Janeiro: IBGE.

Kaale, L. D., Eikevik, T. M., Rustad, T., \& Kolsaker, K. (2011). Superchilling of food: a review. Journal of Food Engineering, 107(2), 141-146. http://dx.doi.org/10.1016/j.jfoodeng.2011.06.004.

Kaale, L. D., \& Eikevik, T. M. (2013). A histological study of the microstructure sizes of the red and white muscles of Atlantic salmon (Salmo salar) fillets during superchilling process and storage. Journal 
of Food Engineering, 114(2), 242-248. http://dx.doi.org/10.1016/j. jfoodeng.2012.08.003.

Kane, H. M., Starkweather, A. W., \& Boyd, D. (1997). Handbook offood engineering practice. Boca Raton: CRC Press.

Margeirsson, B., Pálsson, H., Popov, V., Gospavic, R., Arason, S., Sveinsdóttir, K., \& Jónsson, M. (2012). Numerical modelling of temperature fluctuations in superchilled fish loins packaged in expanded polystyrene and stored at dynamic temperature conditions. International Journal of Refrigeration, 35(5), 1318-1326. http://dx.doi. org/10.1016/j.ijrefrig.2012.03.016.

Martino, M. N., \& Zaritzky, N. (1989). Ice recrystallization in a model system and in frozen muscle tissue. Cryobiology, 26(2), 138-148. PMid:2707029. http://dx.doi.org/10.1016/0011-2240(89)90044-8.
Melorose, J., Perroy, R., \& Careas, S. (2015). Handbook of seafood and seafood products analysis (Vol. 1). Boca Raton: CRC Press.

Mohr, V., \& Reid, D. S. (1985). Scanning electron microscopic study of rockfish preserved at either ambient temperature or by isothermal freeze-fixation. Food Structure, 4(1), 11-16.

Payne, S. R., Sandford, D., Harris, A., \& Young, O. A. (1994). The effects of antifreeze proteins on chilled and frozen meat. Meat Science, 37(3), 429-438. PMid:22059547. http://dx.doi.org/10.1016/03091740(94)90058-2.

Zaritzky, N. E., \& Martino, M. N. (1988). Ice crystal size modifications during frozen beef storage. Journal of Food Science, 53(6), 1631-1637. http://dx.doi.org/10.1111/j.1365-2621.1988.tb07802.x. 